Gut, 1975, 16, 973-978

\title{
Glucagon and the colon
}

\author{
I. TAYLOR, H. L. DUTHIE, D. C. CUMBERLAND, AND R. SMALLWOOD
}

From the Departments of Surgery, Radiology, and Medical Physics, The Royal Infirmary, Sheffield

SUMMARY The effect of glucagon on human colonic myoelectrical activity is described. By means of intraluminal, serosal, and surface electrodes, recordings from all areas of the large bowel have been obtained. Glucagon inhibited both electrical and pressure rhythms in all subjects tested. Evidence is produced to suggest a direct action on colonic smooth muscle. A controlled trial using glucagon during routine barium enema examinations suggests that it may prove to be useful for hypotonic examinations of the colon where painful spasm is present.

Few humoral substances have been shown to inhibit colonic smooth muscle: 5-hydroxytryptamine probably by a direct action (Misiewicz et al., 1966); cholecystokinin in patients with the irritable colon syndrome (Harvey and Read, 1973), and bradykinin in patients with diarrhoea (Murrell and Deller, 1967).

We have studied the action of a further hormone, glucagon, on colonic myoelectrical activity. Glucagon is a polypeptide of molecular weight 3489 and is produced exclusively by the $\alpha_{2}$ cells in the pancreatic islets. While having its main action on glucose metabolism, it has been shown to inhibit intestinal smooth muscle in the jejunum of man (Dotevall and Koch, 1963) as well as the stomach and duodenum in the dog (Necheles et al., 1966). It has also been used empirically in treating acute diverticulitis (Daniel et al., 1973) and we have sought an objective basis for treatment by studying the effect of glucagon on the myoelectrical activity of the colon.

\section{Methods}

The myoelectrical activity from the colon and rectum was recorded in 22 patients using three types of electrode: intraluminal suction electrodes, serosal electrodes, and surface electrodes (Table 1). Motor activity was recorded by means of thin open-ended tubes in patients studied with the intraluminal electrodes. The signals obtained were amplified (AC amplifier with a frequency response $\pm 3 \mathrm{db}$ of $0.02 \mathrm{H}_{\mathrm{z}}$ to $1 \mathrm{KH}_{\mathrm{z}}$ ) and fed into a U-V recorder. The techniques involved have been previously described in detail (Taylor et al., 1974a, b; Taylor et al., 1975).

Received for publication 24 September 1975.

\begin{tabular}{llll}
\hline Site & \multicolumn{3}{l}{ Type of electrode } \\
\cline { 2 - 4 } & Intraluminal & Serosal & Surface \\
\hline Rectosigmoid & 15 & - & - \\
Descending colon & 2 & - & 9 \\
Transverse colon & - & 2 & - \\
Ascending colon and caecum & - & 2 & 5 \\
\hline
\end{tabular}

Table 1 Number of recordings

Recordings were made for 60 minutes at rest and after the intravenous administration of bolus doses of glucagon $(0.5-20 \mu \mathrm{g} / \mathrm{kg}$ body weight). Six patients were given sequentially increasing doses ranging from $0.5 \mu \mathrm{g} / \mathrm{kg}$ to $20 \mu \mathrm{g} / \mathrm{kg}$. Blood sugar estimations were performed before and two minutes, five minutes, and 10 minutes after each dose (group A). Two further subjects were given sequentially decreasing doses $(10 \mu \mathrm{g}, 5 \mu \mathrm{g}$, and $2.5 \mu \mathrm{g} / \mathrm{kg})$ and two subjects the same dose on two occasions $(5 \mu \mathrm{g} / \mathrm{kg}$ and $2.5 \mu \mathrm{g} / \mathrm{kg}$ ) - group B. Finally, a further five subjects were given a single dose $(10 \mu \mathrm{g} / \mathrm{kg})$-group C.

The effect of adrenergic blocking drugs was observed by studying the response in patients on hypotensive therapy. Two patients were taking methyldopa, two patients guanethidine (an adrenergic blocker), and one patient oxyprenolol (a $\beta$-adrenergic blocker). Also glucagon $(10 \mu \mathrm{g} / \mathrm{kg})$ was administered after an initial dose of the $\beta$-adrenergic blocker propranalol in two patients.

Separate studies were performed to ensure that the response was specific to glucagon and not created either by:

1. An intravenous injection-an equal quantity of normal saline was given.

2. The effect of an increase in glucose concentration 
in the blood-20 ml $20 \%$ glucose (which gave a similar change to that after glucagon) was given intravenously.

The frequency and amplitude of the slow wave electrical activity was noted before and after glucagon. The time during which regular slow wave activity was present was expressed as a percentage of total recording time (percentage electrical activity). The percentage of time occupied by pressure waves was also noted from intraluminal recordings (percentage motility).

A separate study was performed to visualize the colonic effect of glucagon. Sixty patients undergoing routine barium enema examinations were randomly allocated to receive either $0.75 \mathrm{ml}$ glucagon (31 patients) or $0.75 \mathrm{ml}$ normal saline (29 patients) intravenously two minutes before screening occurred. The same radiologist (D.C.C.) performed all the investigations and reported on the films without knowledge of the type of injection given. Particular note was made of the amount of discomfort and the degree of colonic spasm encountered during the examination. The time taken for the barium to reach the caecum was also recorded. A comparison of the degree of evacuation of barium in the two groups was made.

\section{Results}

\section{MYOELECTRICAL STUDY}

Glucagon inhibited both slow wave electrical activity and motility throughout the colon and rectum (Fig. 1). The response occurred in all but two of the subjects tested. In these two subjects the recordings were from the descending colon via a left iliac fossa colostomy but the dose administered may have been too small (see later). Inhibition of both the faster (6-11 c/m, 0.10-0.18 Hz) and slower $(2-4 \mathrm{c} / \mathrm{m}, 0.033$ $0.066 \mathrm{~Hz}$ ) electrical rhythms occurred depending upon which happened to be present at the time of administration. The characteristics of the slow wave activity before glucagon were comparable with the value noted in previous studies (Taylor et al., 1974b) -Table 2. The time for the response to occur varied along the bowel. In the rectosigmoid, inhibition occurred 20-90 seconds after injection (mean 48.1 seconds). In the remainder of colon the period was longer-for example, in the transverse colon using implanted electrodes a mean of 190 seconds elapsed before inhibition occurred. Nevertheless, the differences were not statistically significant (Table 3).

The duration of inhibition depended both upon the dose of glucagon and its timing. In four of the six

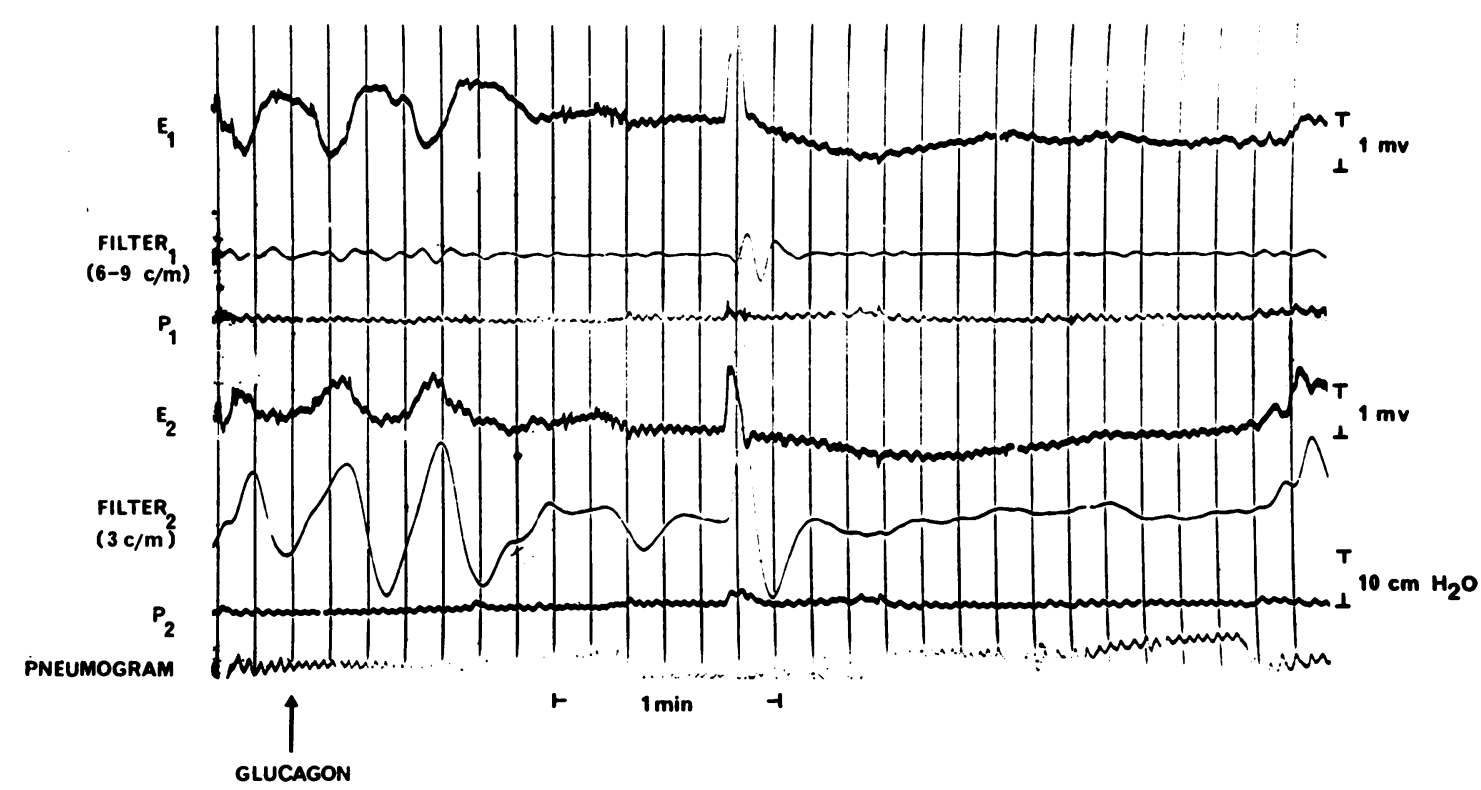

Fig. 1 Recording obtained by intraluminal electrodes at $13 \mathrm{~cm}$ and $8 \mathrm{~cm}$ from the anus showing a predominant $3 \mathrm{c} / \mathrm{m}$ slow wave electrical rhythm $\left(E_{1}\right.$ and $\left.E_{2}\right)$. Approximately 60 seconds after the administration of glucagon $(10 \mu \mathrm{g} / \mathrm{kg})$ a complete inhibition of both electrical and pressure activity $\left(P_{1}\right.$ and $\left.P_{2}\right)$ occurs lasting for three minutes 40 seconds (10 second markers). 


\begin{tabular}{|c|c|c|c|c|c|c|}
\hline \multirow[t]{2}{*}{ Site } & \multicolumn{2}{|c|}{ Frequency c/m (Hz) } & \multicolumn{2}{|c|}{ Amplitude $(m V)$} & \multicolumn{2}{|c|}{ Percentage electrical activity } \\
\hline & Slow & Fast & Slow & Fast & Slow & Fast \\
\hline \multicolumn{7}{|c|}{$\begin{array}{l}\text { Rectosigmoid } \\
\text { Distance from anus (cm) }\end{array}$} \\
\hline $5-9$ & $\begin{array}{c}3.13 \pm 0.18 \\
(0.050 \pm 0.003)\end{array}$ & $\begin{array}{l}7.13 \pm 0.5 \\
(0.11 \pm 0.008)\end{array}$ & $1 \cdot 18 \pm 0 \cdot 04$ & $0.67 \pm 0.07$ & $40 \cdot 0 \pm 15 \cdot 8$ & $56.6 \pm 19.8$ \\
\hline $10-14$ & $\begin{array}{l}2.87 \pm 0.08 \\
(0.046 \pm 0.001)\end{array}$ & $\begin{array}{l}7 \cdot 15 \pm 0.19 \\
(0.11 \pm 0.003)\end{array}$ & $1 \cdot 19 \pm 0.05$ & $0.65 \pm 0.04$ & $22 \cdot 4 \pm 11 \cdot 3$ & $23 \cdot 2 \pm 4 \cdot 35$ \\
\hline $15-19$ & $\begin{array}{l}2.87 \pm 0.08 \\
(0.046 \pm 0.001)\end{array}$ & $\begin{array}{l}7.34 \pm 0.44 \\
(0.12 \pm 0.007)\end{array}$ & $1 \cdot 12 \pm 0 \cdot 14$ & $0.68 \pm 0.07$ & $14.5 \pm 5.9$ & $20.6 \pm 3.14$ \\
\hline $20-24$ & $\begin{array}{l}2.6 \pm 0.1 \\
(0.046 \pm 0.001)\end{array}$ & $\begin{array}{l}8.75 \pm 0.5 \\
(0.14 \pm 0.008)\end{array}$ & $1 \cdot 1 \pm 0 \cdot 2$ & $0.6 \pm 0.10$ & 20 & 15 \\
\hline$>25$ & $\begin{array}{l}2.5 \pm 0.13 \\
(0.04 \pm 0.002)\end{array}$ & $\begin{array}{l}10.5 \pm 1.15 \\
(0.17 \pm 0.028)\end{array}$ & $1 \cdot 15 \pm 0.12$ & $0.7 \pm 0.15$ & $11 \cdot 5$ & 15 \\
\hline \multicolumn{7}{|c|}{ 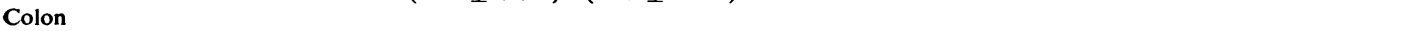 } \\
\hline Transverse & $\begin{array}{l}2.9 \\
(0.046)\end{array}$ & $\begin{array}{l}9 \cdot 8 \\
(0 \cdot 16)\end{array}$ & $1 \cdot 1$ & 0.51 & $11 \cdot 2$ & $65 \cdot 7$ \\
\hline Ascending & $\begin{array}{l}3.0 \pm 0.1 \\
(0.048 \pm 0.001)\end{array}$ & $\begin{array}{ll}10.6 \pm 0.20 \\
(0.17 \pm 0.003)\end{array}$ & $0.87 \pm 0.1$ & $0.56 \pm 0.06$ & $6 \cdot 8 \pm 3 \cdot 2$ & $71 \cdot 1 \pm 7 \cdot 7$ \\
\hline Caecum & $\begin{array}{l}2.9 \pm 0.28 \\
(0.046 \pm 0.003)\end{array}$ & $\begin{array}{l}10.0 \pm 0.15 \\
(0.16 \pm 0.002)\end{array}$ & $0.6 \pm 0.1$ & $0.3 \pm 0.05$ & $21 \cdot 4 \pm 3 \cdot 2$ & $50 \cdot 4 \pm 12 \cdot 5$ \\
\hline
\end{tabular}

Table 2 Mean slow wave characteristics before glucagon administration (mean $\pm 1 S E M$ )

\begin{tabular}{|c|c|c|c|c|}
\hline \multirow[t]{2}{*}{ Distance from anus $(\mathrm{cm})$} & \multicolumn{2}{|l|}{ Rectosigmoid } & \multicolumn{2}{|l|}{ Descending colon } \\
\hline & Period to inhibition (min) & Period of inhibition (min) & Period to inhibition (min) & Period of inhibition (min) \\
\hline 12 & $1 \cdot 3$ & $3 \cdot 2$ & 1.08 & 13 \\
\hline 17 & 0.9 & $16 \cdot 5$ & $4 \cdot 0$ & 10 \\
\hline 12 & 0.5 & $5 \cdot 0$ & $1 \cdot 7$ & $3 \cdot 5$ \\
\hline 13 & 0.5 & $5 \cdot 0$ & - & - \\
\hline 15 & 0.5 & $5 \cdot 1$ & 0.5 & $1 \cdot 1$ \\
\hline 13 & 0.9 & $3 \cdot 0$ & - & - \\
\hline 15 & 0.5 & $12 \cdot 0$ & $1 \cdot 1$ & $10 \cdot 5$ \\
\hline 17 & 0.5 & $17 \cdot 3$ & $1 \cdot 5$ & $17 \cdot 0$ \\
\hline 10 & 0.5 & $4 \cdot 0$ & 0.5 & $4 \cdot 0$ \\
\hline
\end{tabular}

Table 3 Comparison of inhibitory periods in rectosigmoid (intraluminal electrode) and descending colon (surface electrode $)$ in subjects after glucagon $(10 \mu \mathrm{g} / \mathrm{kg})$

subjects in group A there was an inverse relationship between the period of inhibition of slow wave activity and the dose (Fig. 2). In group B the duration was invariably less after the second administration of glucagon (Table 4). In the five subjects in whom a single dose $(10 \mu \mathrm{g} / \mathrm{kg}$ ) was given (group C) the duration of inhibition ranged between 3.5-17.3 minutes (mean $7.57 \pm 1.85$ minutes). No one area of the rectosigmoid was more sensitive to the action of glucagon than any other.

Neither an intravenous injection of saline nor $20 \mathrm{ml} 20 \%$ glucose affected the slow wave activity. Also the duration of inhibition with glucagon bore no relationship to the blood sugar level.

It was found that a dose of at least $10 \mu \mathrm{g} / \mathrm{kg}$ was required to elicit inhibition in the descending colon, lower doses had no effect. When recordings were made from two or more areas simultaneously it was seen that the onset of inhibition corresponded but the actual duration varied in the two regions (Table 3).

After inhibition, the slow wave activity returned with no statistically significant alteration in either its frequency or amplitude in all but two subjects. These two recordings were from the rectosigmoid region and the post-inhibitory frequency was $11.1 \mathrm{c} / \mathrm{m}$ $(0.185 \mathrm{~Hz})$ for two minutes $(6.0 \mathrm{c} / \mathrm{m}, 0.01 \mathrm{~Hz}$ preglucagon) and $11.0 \mathrm{c} / \mathrm{m}(0.180 \mathrm{~Hz})$ for 10 minutes ( $6.5 \mathrm{c} / \mathrm{m}, 0 \cdot 108 \mathrm{~Hz}$ pre-glucagon).

Finally, patients taking adrenergic blockers for hypertension and those tested with glucagon after propranolol exhibited slow wave inhibition to the same degree as the other groups (Fig. 3).

\section{BARIUM ENEMA STUDY}

The age and sex distribution of patients in each group were similar. An assessment was made of the degree of discomfort experienced by each patient 


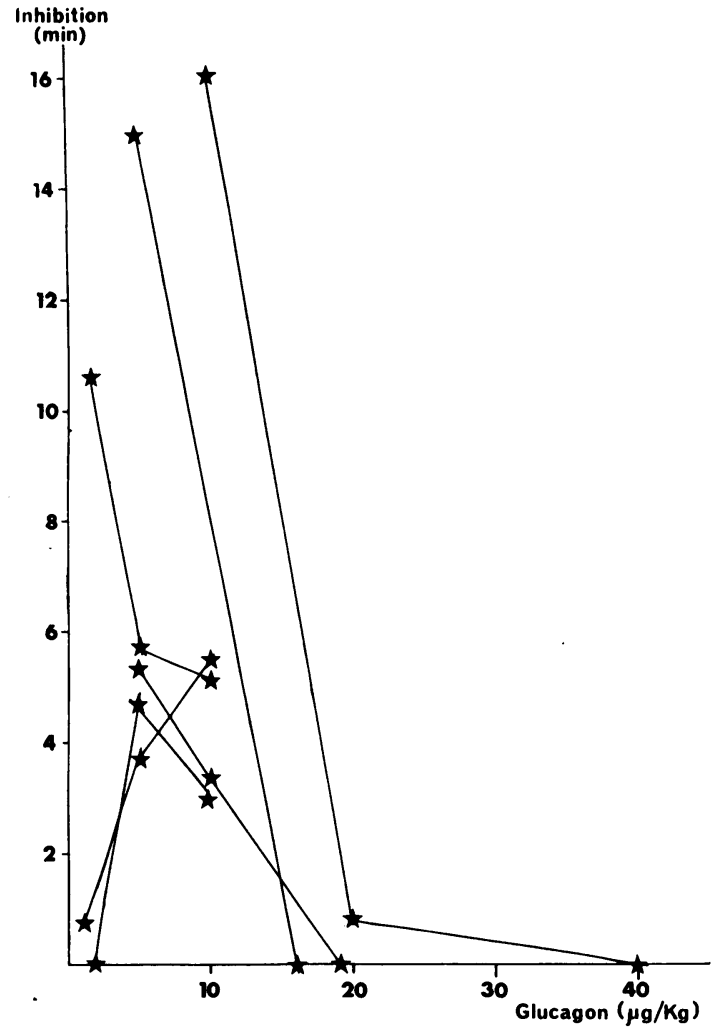

Fig. 2 The mean inhibition of slow wave activity obtained in six subjects after sequentially increasing doses of glucagon.

during the examination. Only one patient experienced severe discomfort (saline group); the remainder experienced either none or a moderate amount. Three patients receiving glucagon had had previous barium enema examinations and each experienced less discomfort with glucagon. There was no statistically significant difference between the two groups (Table 5). Less spasm occurred both on screening and on $x$-ray films among patients in the glucagon group (Table 5). Twenty-five of the 31 patients in the glucagon group had no demonstrable spasm compared with five out of 29 in the control group $(P<0.05)$. Nevertheless, the greatest overall diameter of the colon was similar in each group.

The caecum filled more rapidly in the glucagon group (mean time 100.9 \pm 5.7 seconds compared with $153.1 \pm 18.6$ in the control group). In only five patients did the caecum take more than two minutes to fill, whereas in the control group caecal filling took longer than two minutes in 19 patients.

Post-evacuation films were compared in the two

\begin{tabular}{llcl}
\hline Patient & $\begin{array}{l}\text { Distance } \\
\text { from anus } \\
(\mathrm{cm})\end{array}$ & $\begin{array}{l}\text { Concentration } \\
(\mu \mathrm{g} / \mathrm{kg})\end{array}$ & $\begin{array}{l}\text { Period of } \\
\text { inhibition } \\
(\mathrm{min})\end{array}$ \\
\hline FG (M) & 18 & 10 & $2 \cdot 3$ \\
& & 5 & - \\
AB (F) & 9 & 2 & - \\
& & 20 & $8 \cdot 0$ \\
FF (M) & 11 & 10 & $2 \cdot 5$ \\
& & $12 \cdot 5$ & - \\
& 6 & $12 \cdot 5$ & $3 \cdot 25$ \\
TW (M) & 8 & $12 \cdot 5$ & $3 \cdot 0$ \\
& & $12 \cdot 5$ & $7 \cdot 0$ \\
& & 5 & $2 \cdot 5$ \\
& & 5 & 36 \\
\end{tabular}

Table 4 Slow wave inhibition in subjects in group $B$

\begin{tabular}{|c|c|c|}
\hline & Control (29) & Glucagon (31) \\
\hline \multicolumn{3}{|c|}{ Degree of discomfort } \\
\hline None & 20 & 24 \\
\hline Moderate & 8 & 7 \\
\hline Severe & 1 & 0 \\
\hline Very severe & 0 & $\mathbf{0}$ \\
\hline \multicolumn{3}{|c|}{ Degree of spasm } \\
\hline None & 12 & 25 \\
\hline Moderate & 12 & 6 \\
\hline Severe & 5 & $\mathbf{0}$ \\
\hline Very severe & 0 & $\mathbf{0}$ \\
\hline \multicolumn{3}{|c|}{ Time for barium to reach } \\
\hline caecum $(s)$ & $153 \cdot 1 \pm 18 \cdot 6$ & $\begin{array}{l}100.9 \pm 5.7 \\
P<0.02\end{array}$ \\
\hline
\end{tabular}

Table 5 Barium enema study

groups. No differences could be detected in either the degree of evacuation or the quality of $x$-ray films.

Eight patients had diverticular disease in the saline group and seven in the glucagon group. All but one of the glucagon group had no spasm, whereas in the control three had a severe and three a moderate amount. The mean filling time of the caecum was $88.3 \pm 9 \cdot 1$ seconds in the glucagon compared with $216.2 \pm 58.6$ seconds in the control group $(\mathrm{P}<0.02)$.

\section{Discussion}

Glucagon clearly has an effect on inhibiting colonic activity, presumably by inhibiting the electrical slow wave activity. We have now observed this action in at least one area of the colon in all subjects so far studied. The response is unlikely to be a direct result of the hyperglycaemic effect of glucagon, since intravenous glucose does not mimic the action and the duration of inhibition is not dependent upon the blood sugar level. The theoretical possibility that the periods of inhibition would have occurred without glucagon must be considered; certainly long periods of inhibition do occur naturally (Taylor et al., 1974a). However, the response occurred at all levels 


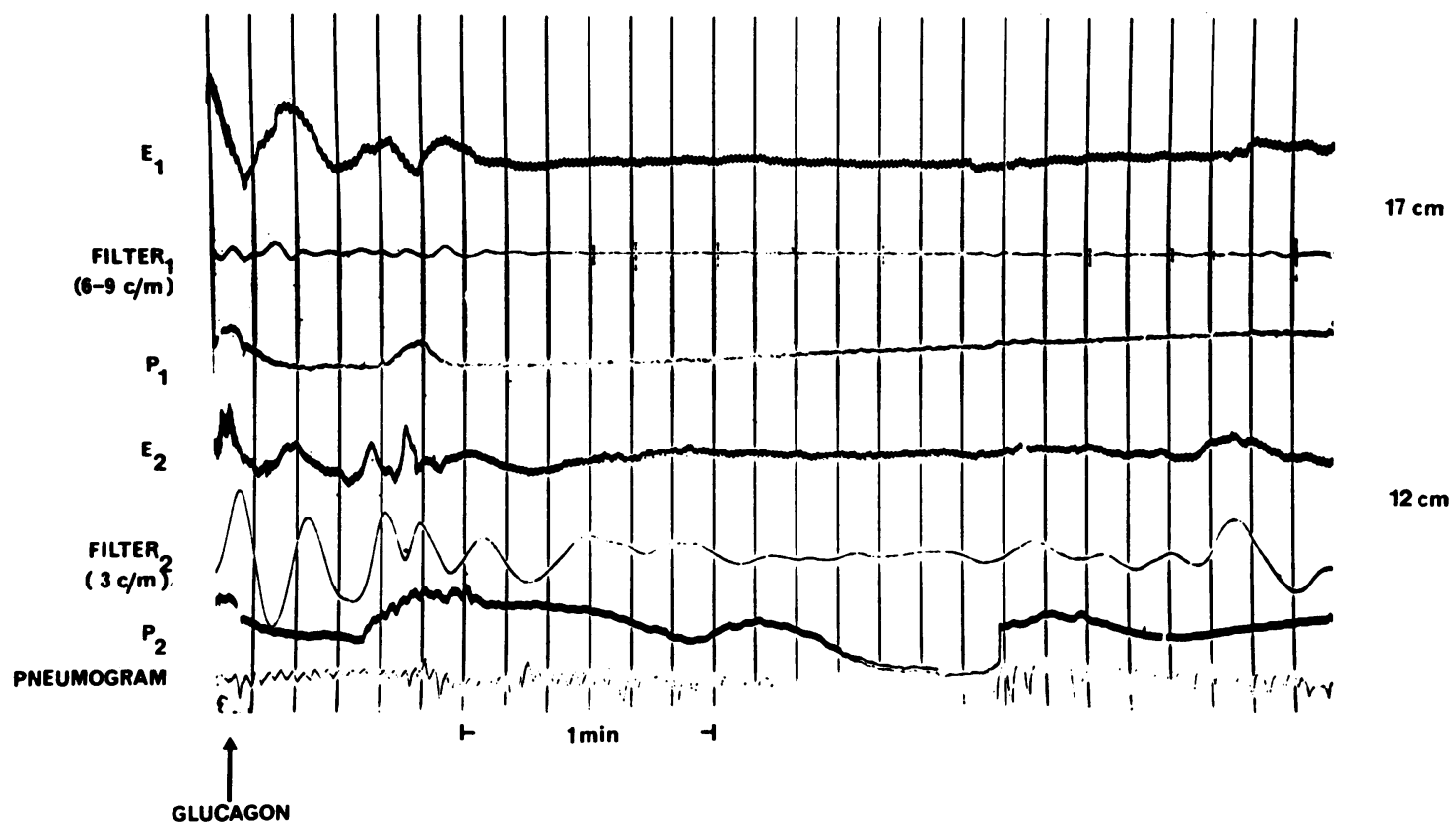

Fig. 3 Recording obtained by intraluminal electrodes $17 \mathrm{~cm}$ and $12 \mathrm{~cm}$ from the anus in a patient taking oxyprenolol (a $\beta$-adrenergic blocker) for hypertension. Glucagon is seen to produce inhibition of both electrical rhythms $\left(E_{1}\right.$ and $\left.E_{2}\right)$ and motility $\left(P_{1}\right.$ and $\left.P_{2}\right)-10$ second markers.

tested even in areas where, before administration, a regular slow wave activity was present for a prolonged period. Also, the inhibition and return of electrical activity occurred simultaneously at two or more recording sites.

The mode of action of glucagon differs from other mediators of colonic relaxation. For instance, atropine acts by competitive blockade at postganglionic parasympathetic junctions and is known to inhibit colonic motility in vitro (Neely and Catchpole, 1967) and in vivo (Misiewicz, 1974). However, in doing so, it preserves the regular slow wave activity and has no effect on either its frequency, amplitude, or incidence (Taylor, 1974). Thus it is reasonable to assume that glucagon does not act in the same way-that is, via parasympathetic blockade.

Another possible role could be as a sympathomimetic agent. Histofluorometric studies have shown that of all the intestinal tissues the taenia coli is the richest in catecholamines (Hollands and Vanov, 1965). Also, whereas adrenaline causes small relaxations of the gastric body, it causes large relaxations of the colon in vitro (Bennett and Whitney, 1966). So a good deal of evidence exists to suggest that the autonomic control of the colon is mediated through the sympathetic nervous system and therefore chiefly inhibitory in nature. However, patients taking adrenergic blockers for hypertension exhibited slow wave inhibition to the same degree as control subjects. This is contrary to what one would expect if glucagon acted as a sympathomimetic agent.

Using a cat colon model in situ, Neely and Catchpole (1967) showed that sympathetic inhibition was mediated mainly through $\beta$ receptors. Contraction occurs after blockade of $\beta$-adrenergic receptors with pronethanol after either adrenaline or noradrenaline (Regoli and Vane, 1964). Bucknell and Whitney (1964) have confirmed these findings with human isolated taenia coli preparations. Thus it seems reasonable to conclude that once the $\beta$ receptors are occupied (or blocked) catecholamines can act on excitory $\alpha$ adrenoreceptors and induce a contraction. Nevertheless, in two subjects after propranolol, glucagon inhibited colonic slow wave activity and motility in the usual way. Thus it seems unlikely that glucagon acts as a sympathomimetic agent.

We feel that a more likely explanation is that glucagon acts directly on colonic smooth muscle. We have previously shown that various drugs 
(pentagastrin, neostigmine) selectively increase the incidence of the slower and faster rhythms (Taylor et al., 1974b); it may well be that glucagon acts directly on smooth muscle selectively increasing the incidence of zero electrical activity.

Successive doses of glucagon were shown to have a decreasing inhibitory response. This phenomenon of 'tachyphylaxis' is usually regarded as due either to blockage of receptor sites or exhaustion of transmitter substances. It may be that glucagon acting directly on colonic smooth muscle 'uses up' the receptor sites responsible for inhibition so that subsequent doses have a diminutive effect. This would further support the concept of a direct inhibitory action.

We were impressed by the use of glucagon in barium enema examinations. Another recent trial confirms these findings (Miller et al., 1974a). Most of the pain and discomfort experienced by patients during barium enema examination is due to spasm within the colon. Glucagon, by producing a hypotonic effect, decreases the amount of spasm significantly, so decreasing the time required for barium to fill the caecum. Unlike the results obtained on the duodenum (Miller et al., 1974b), there is little difference in the diameter of the colon after glucagon. Other drugs which have been used to achieve this effect are less satisfactory. Adverse effects of probanthine and atropine have been described (Gelfand and Moskowitz, 1970; Ferrucci and Benedict, 1971). There have been no reported side-effects to glucagon and none experienced in this trial. Also its short and uniform action make glucagon a very useful drug for hypotonic examination of the colon in those situations where painful spasm is present.

\section{References}

Bennett, A., and Whitney, B. (1966). A pharmacological study of the motility of the human gastrointestinal tract. Gut, 7, 307-316.

Bucknell, A., and Whitney, B. (1964). A preliminary investigation of the pharmacology of the human isolated taenia coli preparation. British Journal of Pharmacology, 23, 164-175.

Daniel, O., Basu, P. K., and Al Samarrai, H. M. (1973).
Glucagon treatment of acute diverticulitis. European Surgical Research, 5, Suppl. 2, 6-7 (Abstract).

Dotevall, G., and Kock, N. G. (1963). The effect of glucagon on intestinal motility in man. Gastroenterology, 45, 364367.

Ferrucci, J. T. Jr, and Benedict, K. T. Jr (1971). Anticholinergic-aided study of the gastrointestinal tract. Radiologic Clinics of North America, 9, 23-29.

Gelfand, D. W., and Moskowitz, M. (1970). Massive gastric dilatation complicating hypotonic duodenography: a report of three cases. Radiology, 97, 637-639.

Harvey, R. F., and Read, A. E. (1973). Effect of cholecystokinin on colonic motility and symptoms in patients with irritable-bowel syndrome. Lancet, 1, 1-3.

Hollands, B. C. S., and Vanov, S. (1965). Localization of catechol amines in visceral organs and ganglia of the rat, guinea-pig and rabbit. British Journal of Pharmacology and Chemotherapy, 25, 307-316.

Miller, R. E., Chernish, S. M., Skucas, J., Rosenak, B. D., and Rodda, B. E. (1974a). Hypotonic colon examination with glucagon. Radiology, 113, 555-562.

Miller, R. E., Chernish, S. M., Skucas, J., Rosenak, B. D., and Rodda, B. E. (1974b). Hypotonic roentgenography with glucagon. American Journal of Roentgenology, 121, 264-274.

Misiewicz, J. J. (1974). Muscular disorders of the colon. British Journal of Hospital Medicine, 11, 191-202.

Misiewicz, J. J., Waller, S. L., and Eisner, M. (1966). Motor responses of human gastrointestinal tract to 5-hydruxytryptamine in vivo and in vitro. Gut, 7, 208-216.

Murrell, T. G. C., and Deller, D. J. (1967). Intestinal motility in man: the effect of bradykinin in the motility of the distal colon American Journal of Digestive Diseases, 12, 568-576.

Necheles, H., Sporn, J., and Walker, L. (1966). Effect of glucagon on gastrointestinal motility. American Journal of Gastroenterology, 45, 34-39.

Neely, J., and Catchpole, B. N. (1967). An analysis of the autonomic control of gastrointestinal motility in the cat. Gut, 8, 230-241.

Regoli, D., and Vane, J. R. (1964). A sensitive method for the assay of angiotensin. British Journal of Pharmacology and Chemotherapy, 23, 351-359.

Taylor, I. (1974). The Myoelectrical Activity of the Human Colon and Rectum. MD Thesis, Sheffield.

Taylor, I., Duthie, H. L., and Smallwood, R. (1975). Large bowel myoelectrical activity in man. Gut, 16, 808-814.

Taylor, I., Duthie, H. L., Smallwood, R., Brown, B. H., and Linkens, D. (1974b). The effect of stimulation on the myoelectrical activity of the rectosigmoid in man. Gut, 15, 599-607.

Taylor, I., Smallwood, R., and Duthie, H. L. (1974a). Myoelectrical activity in the rectosigmoid in man. In Proceedings of the 4th International Symposium on Gastrointestinal Motility, Banff, Alberta, Canada. Mitchell Press. 